\title{
Preparation Technique of Green Tea (Camellia sinensis) in Grins in Mali: Phytochemical Profiles and \\ Antioxidant Activity
}

\author{
Bakary A. Dao \\ Département de Biologie, Faculté des Sciences et Techniques (FST), \\ Université des Sciences, des Techniques et des Technologies de Bamako (USTTB), Mali \\ Tel: 223-7738-6108Ｅ-mail: bakarydao37@yahoo.com
}

Issiaka Togola (Corresponding author)

Département de Biologie, Faculté des Sciences et Techniques (FST),

Université des Sciences, des Techniques et des Technologies de Bamako (USTTB), Mali

Tel: 223-6666-3816 E-mail: togola3@gmail.com

\begin{abstract}
Cheickna Daou
Département de Génie Biologique, Institut des Sciences et Appliquées (ISA), Université des Sciences, des Techniques et des Technologies de Bamako (USTTB), Mali Tel: 223-7637-4722Ｅ-mail: rimma504@yahoo.fr
\end{abstract}

Received: June 5, $2021 \quad$ Accepted: July 12, $2021 \quad$ Published: July 15, 2021

doi:10.5296/jfs.v10i1.18701ＵRL: https://doi.org/10.5296/jfs.v10i1.18701

\begin{abstract}
The tea consumption has become an important part of the Malian's habits. As a result, an image of tea preparation and consumption among Malians has become widely diffused; tea is offered in three successive glasses: the first drink (FD), the second drink (SD) and the third drink (TD). However, no study has been carried out on the antioxidant potential of this type of green tea preparation. The objective of this work was to evaluate the quality of the preparation methods of green tea (Camellia sinensis) as performed in grins. Thus, a
\end{abstract}




\section{MInstitute ${ }^{\text {Mink }}$}

phytochemical screening was carried out, the quantitative estimation of total polyphenols was performed by the method of Folin-Ciocalteu and that of flavonoids by using the aluminum trichloride. The in vitro antioxidant activity of the different tea extracts (macerated and decocted) was determined by the DPPH method. Thus, the presence of several metabolites was revealed in these tea extracts and the cumulative contents of phenolic compounds in the green tea extracts found in the glasses were $150.67 \pm 7.87 \mathrm{mg} \mathrm{EAG} / \mathrm{g}$, while $140.67 \pm 2.37 \mathrm{mg}$ EAG/g were collected in the macerated extract (WM). Both types of extracts showed similar levels of flavonoids. The antioxidant activity of FD in all tea samples was statistically identical to that of the extracts (WM) from tea samples A and D ( $p$-values $>0.05)$. It appears from this preliminary study that neither the total phenolic compound contents nor the antioxidant activity would be impacted by the way Malian green tea is prepared.

Keywords: Camellia sinensis, Tea, Phytoconstituents, Brewing method, Antioxidant activity, Mali

\section{Introduction}

Tea is a drink produced from the leaves of Camellia sinensis (L) O. Kuntze. This drink is extremely popular worldwide and can be served hot or cold (Ramírez-Aristizabal et al., 2017). In Mali, the tea consumption is one of the most common and widespread activities (Bondaz, 2013). Indeed, it has become part of the Malian diet, and is particularly observed in grins. This form of discussion group brings together people of all ages who, in the shade and with a glass of tea, begin a discussion on various subjects (Coulibaly, 2010).

The potential health benefits of tea have been the subject of numerous studies in recent decades (Yang et al., 2017). Tea can improve physical health and physiological function and reduce the risk of cardiovascular disease and cancer (McKay \& Blumberg, 2002).

Tea's health benefits are believed to come from polyphenols, which have antioxidant properties (Komes et al., 2010). Indeed, the main antioxidants in tea are catechins, flavonols, and tannins, and green tea has the most powerful antioxidant of all tea types (Safdar et al., 2016). The antioxidant properties of green tea polyphenols and the pro-oxidant effects of these compounds have made it a potential candidate for cancer prevention (Yashin et al., 2011). Theanine has a potential role in stress reduction, catechins promote weight loss and have antiviral, anti-inflammatory and anti-carcinogenic effects, while theaflavines are associated with reduced cardiovascular risk (Balsaraf \& Chole, 2015). Flavonoids in black and green tea have been implicated in cancer chemoprevention (Hakim 2000).

This beverage, so coveted for its many virtues, is prepared differently depending on the country. For example, in China, tea leaves are soaked in hot water at a temperature between $70^{\circ} \mathrm{C}$ and $80^{\circ} \mathrm{C}$ for $20-40$ seconds, and the same tea leaves are usually soaked repeatedly for about seven times (Safdar et al., 2016). In Mali, decoction is the most popular method of preparation, and is available in three successive glasses (Bondaz, 2013). The leaves are boiled in water for 15 to 20 minutes (the first or first glass). The same leaves are boiled again in water for 20 to 30 minutes (the second or second glass). The leaves are boiled one last time in water for 40 to 50 minutes (the third or third glass). This last glass is rarely found in the grins of adults. According to Bondaz (2013), this glass is reserved for children. The successive glasses are illustrated in Figure 1. 


\section{Macrothink Institute ${ }^{\mathrm{TM}}$}

Given the growing interest in the health properties of tea, especially those with antioxidant power, and given the different types of tea and the different methods of preparing a cup of tea in different countries, which can affect the active ingredient content in the final preparation of this beverage, it becomes necessary to assess antioxidant activity to determine changes between processes (Venditti et al., 2010). For this reason, this study was conducted to determine the total phenolic compounds, flavonoid content, and antioxidant capacity of five different brands of tea sold in Mali and prepared "Malian style".

\section{Material and Methods}

The plant material consists of commercial samples of green tea sold in the markets of Bamako. These samples are composed of $25 \mathrm{~g}$ bags of green tea of five (5) brands (A, B, C, $\mathrm{D}$ and $\mathrm{E})$.

\subsection{Preparation of Extracts}

\subsubsection{Water Maceration (WM)}

These extracts were obtained by macerating $50 \mathrm{~g}$ of green tea powder in $500 \mathrm{~mL}$ of distilled water. The mixture was stirred for 48 hours and then the filtrate was recovered under vacuum.

\subsubsection{First tea or First drink (FD)}

Twenty-five grams of green tea leaves are boiled in $250 \mathrm{~mL}$ of distilled water. After 15 minutes of boiling, the cooled filtrate is recovered and placed at $4{ }^{\circ} \mathrm{C}$ for further analysis.

\subsubsection{Second tea or Second drink (SD)}

To the residue of the first tea is added $250 \mathrm{~mL}$ of distilled water, the whole is boiled for 25 minutes and the cooled filtrate is recovered and placed at $4{ }^{\circ} \mathrm{C}$.

\subsubsection{Third tea or third drink (TD)}

Two hundred and fifty $\mathrm{mL}$ of distilled water is added to the tea leaves from the second tea, the mixture is boiled for 40 minutes. The cooled filtrate is recovered and placed at $4{ }^{\circ} \mathrm{C}$ for further analysis.

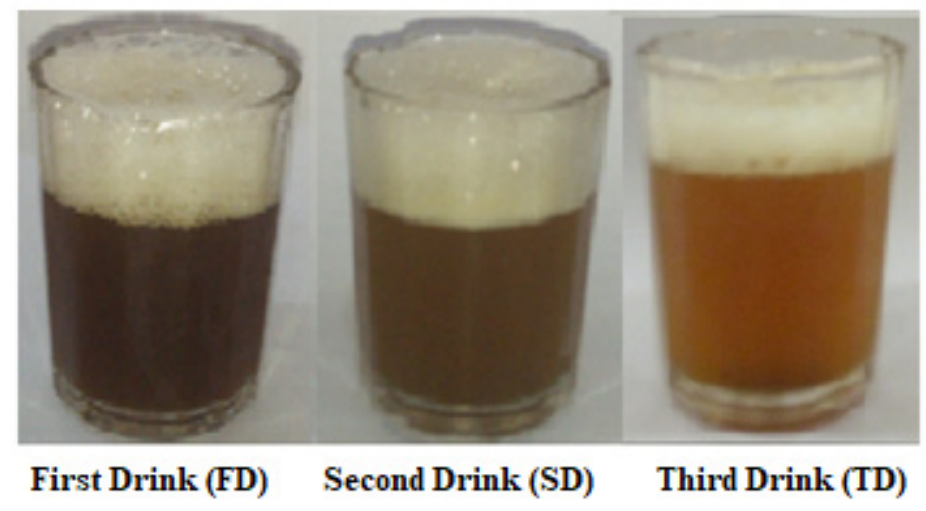

Figure 1. The three successive glasses of green tea "prepared Malian style"

\subsection{Phytochemical Screening}

The extracts were analyzed in order to highlight the different phytochemical groups. The protocols described by Harborne, (1998) and Bruneton (2009) were used. 


\subsection{Dosage of Total Polyphenols}

The contents of phenolic compounds in the various green tea extracts were estimated by the Folin-Ciocalteu method described by Singleton et al. (1999). Thus, $500 \mu \mathrm{L}$ of Folin-Ciocalteu reagent (diluted $10 \%$ in distilled water) is added to $100 \mu \mathrm{L}$ of tea extract and $400 \mu \mathrm{L}$ of disodium carbonate $\left(\mathrm{Na}_{2} \mathrm{CO}_{3}\right)$ at $75 \mathrm{mg} / \mathrm{mL}$ is added to the reaction mixture. After a 2-hour incubation at room temperature and protected from light, the absorbance is read at $765 \mathrm{~nm}$. A calibration curve is performed under the same operating conditions using a gallic acid dilution series. Results are expressed in milligram equivalent of gallic acid per gram of extract (mg EAG/g).

\subsection{Dosage of Total Flavonoids}

The estimation of total flavonoids was carried out according to the method described by Chang et al., (2002). To $1000 \mu \mathrm{L}$ of each extract, $1500 \mu \mathrm{L}$ of $95 \%$ methanol, $100 \mu \mathrm{L}$ of $10 \%$ $\mathrm{AlCl}_{3}(\mathrm{w} / \mathrm{v}), 100 \mu \mathrm{L}$ of $1 \mathrm{M}$ sodium acetate and $2.8 \mathrm{~mL}$ of distilled water were added. The mixture is stirred and incubated in the dark at room temperature for $30 \mathrm{~min}$. The blank is made by replacing the extract with $95 \%$ methanol and the absorbance is measured at $415 \mathrm{~nm}$ using a UV spectrophotometer. The results are expressed in $\mathrm{mg}$ quercetin equivalent/g dry plant matter.

\subsection{In vitro Antioxidant Activity: Scavenging of DPPH Radicals}

The trapping capacity of the stable free radical 1,1-diphenyl 2-picrylhyorazyl (DPPH) of green tea extracts was evaluated according to the spectrophotometric method described by Brand-Williams et al. (1995). A solution of DPPH $(0.1 \mathrm{mM})$ in methanol was mixed with 1 $\mathrm{ml}$ of extract at various concentrations $(2-12 \mu \mathrm{g} / \mathrm{mL})$. At the same time, a mixture of $1 \mathrm{~mL}$ methanol and $1 \mathrm{~mL}$ DPPH solutions was used as a control. The reaction was performed in triplicate and the decrease in absorbance was measured at $517 \mathrm{~nm}$ after 30 minutes incubation of the samples in the dark. The positive control was ascorbic acid whose absorbance was measured under the same conditions as the samples. The antioxidant activity related to the scavenging effect of the DPPH radical is expressed as percent inhibition (PI) calculated from the absorbances obtained according to the following formula:

$$
[\mathrm{PI}]=\frac{A 0-A 1}{A 0} \times 100
$$

A0 = DPPH absorbance; A1: sample absorbance.

The IC50s (concentrations that inhibit 50\% of the DPPH radical) were deduced from the linear regression line obtained from the graph representing the percentage inhibition of DPPH.

\subsection{Data Analysis}

The resulting data were processed using Excel ${ }^{\circledR}$ version 2013 and Minitab 18.1 software. They were expressed as a standard \pm error mean of the mean of three trials. The single-factor ANOVA test using the Fisher test was chosen to compare the polyphenol, flavonoid, and antioxidant activity of different types of extracts (WM, FD, SD, and TD) in commercially available "Malian-style" green tea samples. The p-values below 0.05 were considered statistically significant. 


\section{1l Macrothink}

\section{Results}

\subsection{Phytochemical Screening}

The table 1 presents the results of the phytochemical screening carried out on green tea extracts from aqueous maceration and preparation as carried out in Malian grins. Thus, apart from terpenoids, all the sought-after metabolites were found in the different extracts. The phytochemical profile of the WM extracts is very similar to that of the FD extracts. Metabolites from SD extracts are present at moderate concentrations, in TD extracts, these metabolites are observed in low concentrations, even in trace amounts.

Table 1. Phytochemical screening of green tea extracts marketed in Bamako and prepared according to the Malian model and the WM aqueous macerate (control)

\begin{tabular}{|c|c|c|c|c|c|c|c|c|c|c|c|c|c|c|c|c|c|c|c|c|}
\hline \multirow[b]{2}{*}{ Chemical groups } & \multicolumn{4}{|c|}{ Tea A } & \multicolumn{4}{|c|}{ Tea B } & \multicolumn{4}{|c|}{ Tea C } & \multicolumn{4}{|c|}{ Tea D } & \multicolumn{4}{|c|}{ Tea $\mathbf{E}$} \\
\hline & WM & FD & SD & TD & WM & FD & SD & TD & $\mathbf{W M}$ & FD & SD & TD & WM & FD & SD & TD & WM & FD & SD & TD \\
\hline Alkaloids & +++ & +++ & ++ & + & +++ & +++ & ++ & + & +++ & +++ & ++ & + & +++ & +++ & ++ & + & +++ & +++ & ++ & + \\
\hline Reducing Sugar & ++ & ++ & + & + & ++ & ++ & + & + & ++ & ++ & + & + & ++ & ++ & + & + & ++ & ++ & + & + \\
\hline Tannins & +++ & +++ & ++ & + & +++ & +++ & ++ & + & +++ & +++ & ++ & + & +++ & +++ & ++ & + & +++ & +++ & ++ & + \\
\hline Flavonoids & +++ & +++ & ++ & + & +++ & +++ & ++ & + & +++ & +++ & ++ & + & +++ & +++ & ++ & + & +++ & +++ & ++ & + \\
\hline Coumarins & ++ & + & + & \pm & ++ & + & + & \pm & ++ & + & + & \pm & ++ & + & + & \pm & ++ & + & + & \pm \\
\hline Saponins & +++ & +++ & ++ & + & +++ & +++ & ++ & + & +++ & +++ & ++ & + & +++ & +++ & ++ & + & +++ & +++ & ++ & + \\
\hline Terpenoids & - & - & - & - & - & - & - & - & - & - & - & - & - & - & - & - & - & - & - & - \\
\hline
\end{tabular}

Legend: - : negative $; \pm$ : presence in trace $;+:$ presence in low concentration $;++:$ presence in moderate concentration ; +++ : presence in high concentrations ; WM : Water Maceration ; FD : First Drink ; SD : Second Drink ; TD : Third Drink.

\subsection{Total Polyphenol and Flavonoid Contents}

The spectrophotometric assay revealed the contents of total polyphenols and flavonoids. These results are highlighted in the Figures 2 and 3. Moreover, the total polyphenols and flavonoids of the three glasses (FD, SD and TD) were cumulated (Table 2). This table shows that the content of total polyphenols collected in the three glasses is $150.67 \pm 7.87 \mathrm{mgEAG} / \mathrm{g}$ and this value is significantly different from that obtained with aqueous maceration (140.67 \pm 2.37$)$ with a p-value of 0.026 . On the other hand, with both types of extracts, we noted a statistically similar flavonoid content $(\mathrm{p}$-value $=0.923)$. 


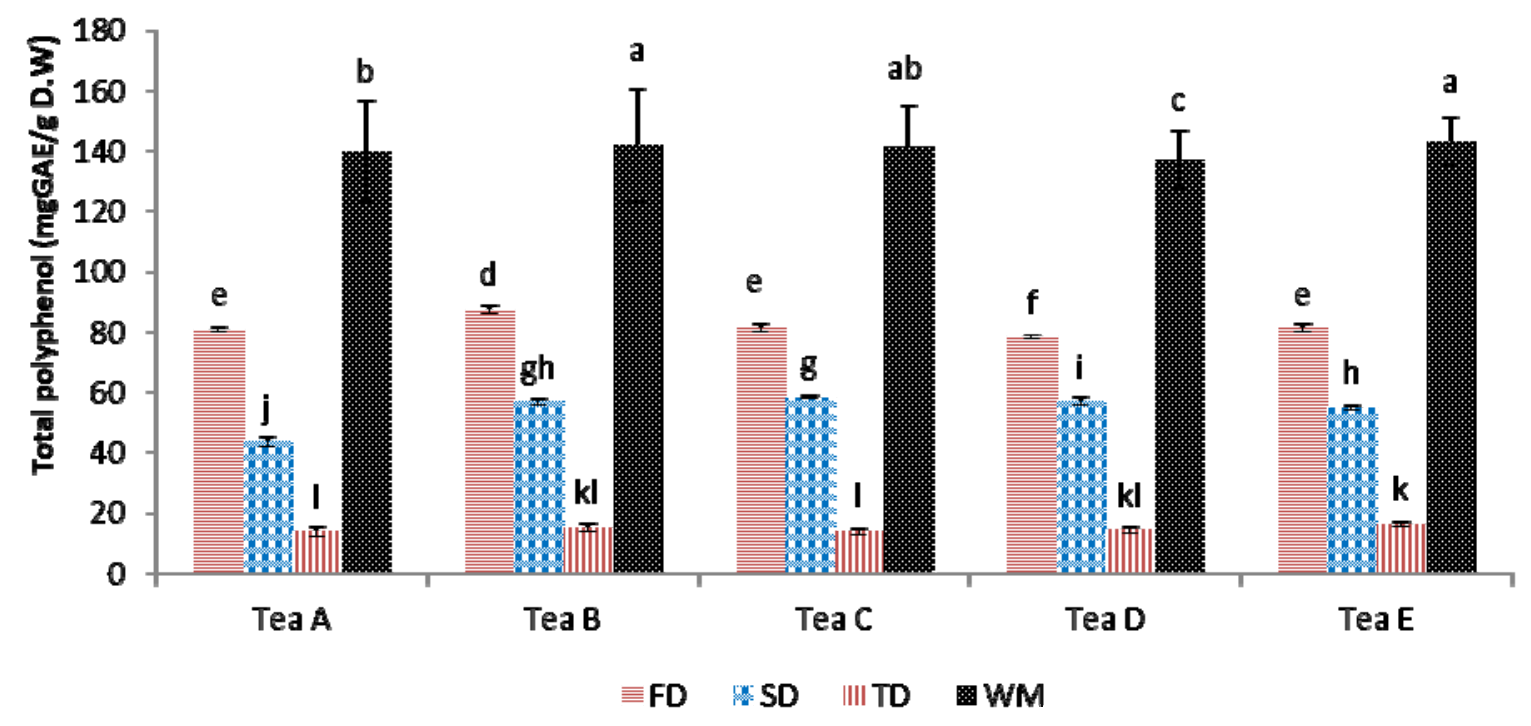

Strips with different letters are significantly different.

Figure 2. Variation of the total polyphenol content in the different extracts of green tea prepared according to the Malian style and the water maceration (WM) control

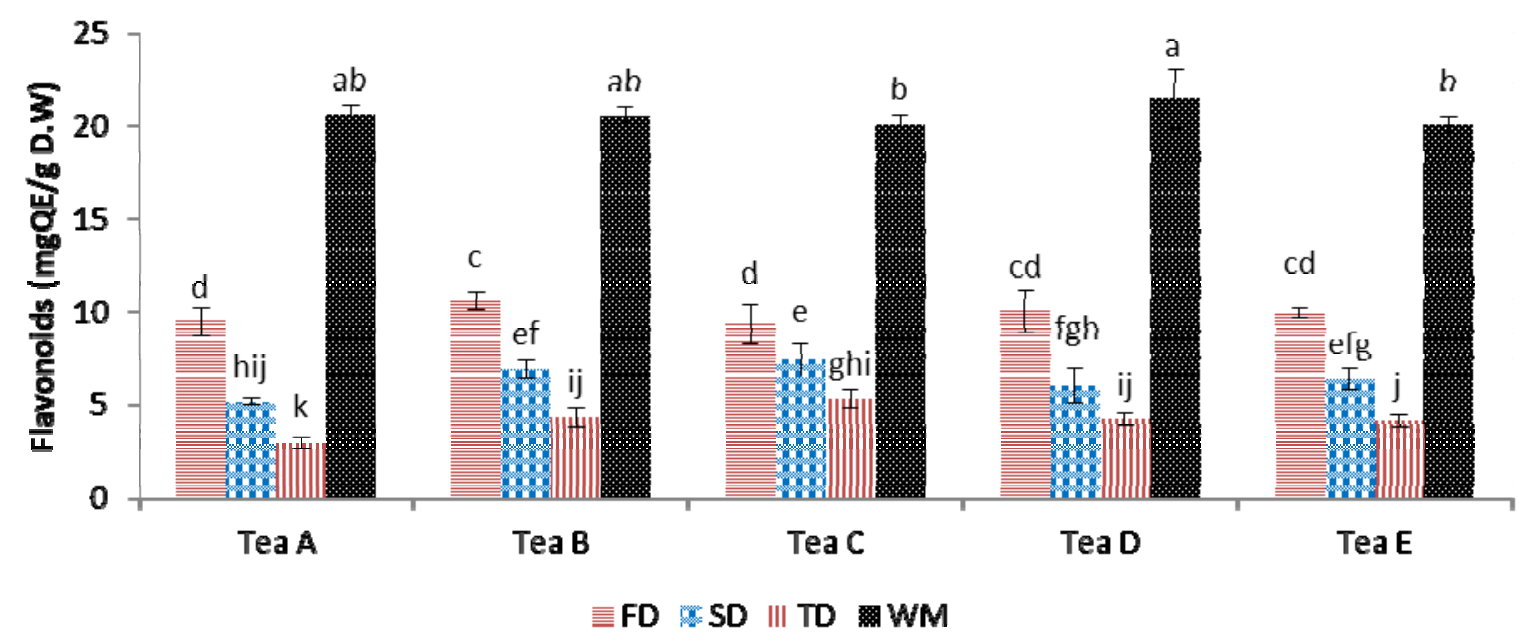

Strips with different letters are significantly different

Figure 3. Variation of flavonoid contents in the different extracts of green tea prepared 


\section{Macrothink}

Table 2. Summary of total polyphenol and flavonoid contents of green tea extracts prepared according to the Malian model and WM aqueous maceration (control) according to the Malian style and the water maceration (WM) control

\begin{tabular}{lllll}
\hline & $\begin{array}{l}\text { Total polyphenols } \\
(\mathbf{m g E A G} / \mathbf{g})\end{array}$ & & $\begin{array}{l}\text { Flavonoids } \\
(\mathbf{m g E Q} / \mathbf{g})\end{array}$ & \\
\hline Samples & FD+SD+TD & WM & FD+SD+TD & WM \\
\hline Tea A & 138.12 & 139.82 & 17.6 & 20.62 \\
Tea B & 159.51 & 141.92 & 21.81 & 20.56 \\
Tea C & 153.68 & 141.56 & 22.07 & 20.09 \\
Tea D & 149.79 & 136.98 & 20.26 & 20.47 \\
Tea E & 152.24 & 143.08 & 20.43 & 20.03 \\
Mean \pm SD & $150.67 \pm 7.87^{\mathrm{a}}$ & $140.67 \pm 2.37^{\mathrm{b}}$ & $20.43 \pm 1.78^{\mathrm{A}}$ & $20.35 \pm 0.27^{\mathrm{A}}$ \\
P-value & 0.026 & & 0.923 & \\
\hline
\end{tabular}

In the penultimate column the means not sharing the same letter are significantly different (lower case for total polyphenols and uppercase for flavonoids).

\subsection{In Vitro Antioxidant Activity of Green Tea Extracts}

The ability of various green tea extracts prepared by the grind method to trap the stable free radical DPPH was determined. The different extracts and ascorbic acid (positive control) have a dose-dependent ability to reduce the DPPH radical (Table 3). Thus, the first glasses of the different samples have similar $\mathrm{IC}_{50}$ ( $\mathrm{p}$-value $>0.05$ ). These $\mathrm{IC}_{50}$ are significantly lower than those of the second glasses. The third glasses have low antioxidant activities compared to the other extracts. The WM extracts of tea samples A and D have an antioxidant activity close to the FD of all green tea samples (p-values between 0.446 and $0.961>0.05$ ). Also, the scavenging capacity of the WM extracts from samples B, C and E) are statistically identical to the DF of tea $\mathrm{A}(\mathrm{p}$-values $=0.667,0.074$ and $0.175>0.05)$.

Table 3. IC50 variations of different green tea extracts prepared according to the Malian model and the WM aqueous macerate (control)

\begin{tabular}{llllll}
\hline \multicolumn{5}{l}{ DPPH radical $\mathrm{IC}_{50}(\boldsymbol{\mu g} / \mathbf{m l})$} \\
\hline Preparation & Tea A & Tea B & Tea C & Tea D & Tea E \\
First Drink & $497.4 \pm 32.4^{\mathrm{defg}}$ & $512.62 \pm 11.91^{\mathrm{de}}$ & $502.6 \pm 38.1^{\mathrm{def}}$ & $523.2 \pm 44.8^{\mathrm{d}}$ & $505.6 \pm 31.4^{\mathrm{de}}$ \\
Second Drink & $731.1 \pm 34.9^{\mathrm{c}}$ & $716.85 \pm 16.05^{\mathrm{c}}$ & $738.3 \pm 28.7^{\mathrm{c}}$ & $761.93 \pm 8.10^{\mathrm{c}}$ & $739.9 \pm 28.30^{\mathrm{c}}$ \\
Third Drink & $1076.5 \pm 108.6^{\mathrm{b}}$ & $1142.3 \pm 57.2^{\mathrm{a}}$ & $1053.81 \pm 13.81^{\mathrm{b}}$ & $1015.4 \pm 20.3^{\mathrm{b}}$ & $1035.2 \pm 59.3^{\mathrm{b}}$ \\
Water Maceration & $508.1 \pm 22.3^{\mathrm{de}}$ & $438.01 \pm 18.7^{\mathrm{g}}$ & $439.55 \pm 14.10^{\mathrm{fg}}$ & $521.65 \pm 10.51^{\mathrm{d}}$ & $453.9 \pm 25.7^{\mathrm{efg}}$ \\
Ascorbic Acid & $53.61 \pm 2.07$ & & & & \\
\hline
\end{tabular}




\section{Discussion}

Green tea is a very popular product in the Republic of Mali. It is consumed by more than two thirds of the population of all ages and sexes (Dembélé, 2008). However, there are no studies on the content of phenolic compounds and the antioxidant capacity of green tea prepared according to the Malian grin model. In this study, five brands of green tea were subjected to this type of hot water extraction to determine their chemical profiles, assess their phenolic compound and flavonoid content and their ability to trap the DPPH free radical. Thus, the phytochemical screening of these different green tea extracts reveals the presence of alkaloids, reducing sugars, tannins, flavonoids, coumarins and saponins. The presence of these metabolites in green tea has already been reported by other authors (Narmada et al., 2020; Ananthi \& Sagaya, 2018; Tariq \& Reyaz, 2012). The different virtues attributed to green tea are said to be due to these phytomolecules, especially flavonoids, which are strongly represented in green tea by catechins. These tea catechins consist mainly of four compounds, namely (-)-epigallocatechin-3-gallate, which accounts for about $59 \%$ of the total catechin content; (-)-epigallocatechin (19\%); (-)-epicatechin-3-gallate (13.6\%); and (-)-epicatechin (6.4\%) (Pasrija \& Anandharamakrishnan, 2015).

Total polyphenol content and antioxidant activity are two parameters for tea quality control and both tests should be applied for tea quality control (Anesini et al., 2008). Thus, in this study, the levels of total phenolic compounds and flavonoids were evaluated. In the three glasses of tea served in the grins, the total phenolics and flavonoids in FD were higher than those in SD, which in turn had significant levels compared to TD. This method of preparation is actually an aqueous extraction by exhaustion. The low TD content of these compounds in TD could justify the fact that this glass is reserved for children (Bondaz, 2013). The flavonoid content of green tea extracted by aqueous maceration (WM) is close to that of FD, SD and TD combined. However, at the level of total phenolic compounds, the cumulative content of FD, SD and TD is higher than that of WM (p-value=0.026). This may be due to the fact that total phenolic compounds are better extracted hot than cold (Ramírez-Aristizabal et al., 2017; Venditti et al., 2010). Also, this demonstrates that the way green tea is prepared as it is done in the grins does not impact the amount of phenolic compounds and flavonoids in green tea. It should also be noted that the average total polyphenol content of the three glasses is $150.67 \pm 7.87 \mathrm{mgEAG} / \mathrm{g}$ or $15.067 \%$. This result is comparable to the work of Anesini et al. (2008) carried out in Argentina, on green teas marketed in this country whose total phenolic compound content ranged from 14.32 to $21.02 \% \mathrm{EAG}$.

The green tea extracts with the highest total phenolic content showed the best antioxidant activities. According to several authors, there is a correlation between the content of total phenolic compounds and antioxidant activity (Dembélé et al., 2020; Konaré et al., 2020; Ramírez-Aristizabal et al., 2017; Safdar et al., 2016). Also, according to Horžić et al. (2009), the antioxidant capacity of tea is not related only to one or a few phytochemical compounds present in plants, but is widely distributed among a series of phenolic compounds, including catechins. Thus, the order of antioxidant activity of the various green tea extracts was as follows: FD > SD > TD. In this study, the antioxidant activity of the extracts (WM) from the tea samples (A and D) is close to that of the DF from all samples (Table 3). This shows that the way tea is prepared as performed in the Malian grins does not seem to affect the 
antioxidant activity of green tea. The green teas used in this study showed similar antioxidant activity at the DF level, which could be explained by the fact that green teas consumed in Mali are mostly imported from the same area, China.

\section{Conclusion}

The present study highlighted the phytochemical profile and antioxidant potential of successive glasses of green tea served in Mali (the first, second and third). The richness of these glasses in secondary metabolites such as alkaloids, flavonoids, tannins and saponosides was observed, with a concentration of these elements decreasing from the first to the third glass. This trend was confirmed by the determination of total phenolic compounds and flavonoids. Also, the cumulative content of total phenolic compounds in the three glasses is significantly higher than that of the macerated green tea extracts. The antioxidant potential of green tea differed between glasses. Indeed, the richer the glass is in total phenolic compounds, the higher the antioxidant potential. The third tea had the lowest antioxidant activity. In addition, the first of some tea samples had an antioxidant potential similar to that of the macerated green tea extract. Thus, neither the total phenolic compounds nor the antioxidant potential seemed to be affected by the way the tea was prepared in the Malian grins. However, further studies are needed to evaluate this method of tea preparation on other phytoelements such as groups of catechins whose stability depends on the time and temperature of tea cooking.

\section{Référence}

Ananthi, J., \& Sagaya, G. R. (2018). Screening of bioactive compounds of green tea (Camellia sinensis). World Journal of Pharmaceutical and Medical Research, 4(9), 222-226.

Anesini C., Ferraro G. E., \& Filip R. (2008). Total polyphenol content and antioxidant capacity of commercially available tea (Camellia sinensis) in Argentina. J. Agric. Food Chem., 56(19), 9225-9229. https://doi.org/10.1021/jf8022782

Balsaraf, S., \& Chole, R. (2015). Green tea: its potential health implications and other benefits. International Journal of Nutrition, Pharmacology, Neurological Diseases, 5, 46-49. https://doi.org/10.4103/2231-0738.153791

Brand, W. W., Cuvelier, M. E., \& Berset, C. (1995). Use of free radical method to evaluate anti-oxidant activity. Lebensmittel Wissenschaft and Technologie, 28(1), 25-30. https://doi.org/10.1016/S0023-6438(95)80008-5

Bruneton, J. (2009). Pharmacognosie, Phytochimie et plantes médicinales. 4ème Edition. Technique et Documentation, p. 1268.

Chang, C., Yang, M., Wen, H., \& Chern, J. (2002). Estimation of total flavonoids content in propolis by two complementary colorimetric methods. J Food Drug Analysis, 10, 178-182.

Coulibaly, N. (2010). Comment la communication peut-elle servir d'interface au développement du Mali ? Exemple des capsules de Télékotèba. Mémoire de Maîtrise en Communication. Université de Québec à Montréal.

Dembélé, J., Togola, I., Daou, C., Diarra, N., Konaré, M. A., \& Sanogo, R. (2020). Evaluation of the antioxidant activity of some plants used in the management of erectile dysfunction by the BWA community in Mali. Journal of Drug Delivery and Therapeutics, 10(6), 57-61. https://doi.org/10.22270/jddt.v10i6.4559 


\section{Macrothink}

Dembélé, M. L., (2008). Contrôle de la qualité physicochimique et bactériologique des thés verts consommés au Mali. Thèse de Pharmacie, Université de Bamako.

Harborne J. B. (1998). Phytochimical Methods: A guide to moderne techniques of plant analysis: chapman and hill.1998. 303p.

Horžić, D., Komes, D., Belščak, A., Ganić, K. K., Ivekovic, D., \& Karlović, D. (2009). The composition of polyphenols and methylxanthines in teas and herbal infusions. Food Chem, 115(2), 441-448. https://doi.org/10.1016/j.foodchem.2008.12.022

Ida Bagus Narmada, B. I., Sarasati, A., Wicaksono, S., Rezkita, F., Kadek Gede Putra Wibawa, K. G. P., Hayaza, S., \& Nugraha A. P. (2020). Phytochemical Screening, Antioxidant Activity, Functional Groups and Chemical Element Characterization Analysis of (-)-Epigallocatechin-3-Gallate (EGCG) in East Javanese Green Tea Methanolic Extract: An Experimental In Vitro Study. Sys Rev Pharm, 11(5), 511-519.

Komes, D., Horžić, D., Belščak, A., Ganić, K. K., \& Vulić, I. Green tea preparation and its influence on the content of bioactive compounds. Food Res Int., 43(1), 167-76. https://doi.org/10.1016/j.foodres.2009.09.022

Konaré, M. A., Diarra, N., Cissé, C., Traoré, D. A. K., Togola, I, Kassogué, A., ... Ouattara, A. S. (2020). Evaluation of the biological activities of leaf and bark extracts of Ficus platiphylla Delile, a medicinal plant used in Mali. Journal of Medicinal Plants Research, 14(3), 118-128. http://doi.org/10.5897/JMPR2019.6874

McKay, D. L., \& Blumberg, J. B. (2002). Review-The role of tea in human health : an update. J. Am. Coll. Nutr., 21, 1-13. https://doi.org/10.1080/07315724.2002.10719187

Pasrija, D., \& Anandharamakrishnan, C. (2015). Techniques for extraction of green tea polyphenols: A review. Food Bioprocess Technol, 8(5), 935-50. https://doi.org/10.1007/ s11947-015-1479-y

Ramírez-Aristizabal, L. S., Ortíz, A., Restrepo-Aristizabal, M. F., \& Salinas-Villada, J. F. (2017). Comparative study of the antioxidant capacity in green tea by extraction at different temperatures of four brands sold in Colombia. Vitae, 24(2), 132-145. https://doi.org/10. 17533/udea.vitae.v24n2a06

Singleton, V. L., Orthofer, R., \& Lamuela-Raventos, R. M. (1999). Analysis of total phenols and other oxidation substrates and antioxidants by means of Folin-Ciocalteu Reagent. Methods Enzymol., 299, 152-178. https://doi.org/10.1016/S0076-6879(99)99017-1

Tariq. A. L., \& Reyaz. A. L. (2012). Phytochemical analysis of Camellia sinensis Leaves" Int. J. Drug Dev. \& Res., 4(4), 311-316.

Venditti, E., Bacchetti, T., Tiano, L., Carloni, P., Greci, L., \& Damiani, E. (2010). Hot vs. cold water steeping of different teas: Do they affect antioxidant activity? Food Chem., 119(4), 1597-604. https://doi.org/10.1016/j.foodchem.2009.09.049

Yang, C. S., Wang, H., \& Sheridan, Z. P. (2017). Studies on prevention of obesity, metabolic syndrome, diabetes, cardiovascular diseases and cancer by tea. J. Food Drug Anal, 26, 1-13. https://doi.org/10.1016/j.jfda.2017.10.010 


\section{Macrothink}

Journal of Food Studies

ISSN 2166-1073 2021, Vol. 10, No. 1

Yashin, A., Yashin, Y., \& Nemzer, B. (2011). Determination of antioxidant activity in tea extracts, and their total antioxidant content. American Journal of Biomedical Sciences, 3(4), 322-335. https://doi.org/10.5099/aj110400322

\section{Copyright Disclaimer}

Copyright for this article is retained by the author(s), with first publication rights granted to the journal.

This is an open-access article distributed under the terms and conditions of the Creative Commons Attribution license (http://creativecommons.org/licenses/by/4.0/). 